\title{
Effect of unilateral adrenalectomy on the quality of life of patients with lateralized primary aldosteronism
}

\author{
Marilisa Citton', Giovanni Viel', Francesca Torresan', Gian Paolo Rossi ${ }^{2}$ and Maurizio lacobone ${ }^{1 *}$ (D)
}

\begin{abstract}
Background: Primary aldosteronism (PA) is associated with an increased prevalence of anxiety and depression. Subnormal quality of life (QoL) scores in PA patients may be improved after surgical treatment. The aim of the study was to assess the impact of surgery on health-related QoL and depression status of patients suffering from PA, comparing the results with a control group of patients undergoing surgery for non-secreting adrenal tumors.

Methods: Data on QoL and depression status were prospectively collected, from January 2014 to January 2017, before, early after surgery (at 1 month) and at late follow up (at least 6 months) in patients with unilateral PA and in a control group with non-secreting adrenal tumors submitted to unilateral laparoscopic adrenalectomy. QoL was assessed using the Short Form 36 (SF-36) Health Survey for Physical (PCS) and Mental Component (MCS); the depression status by a 20-item depression scale (DS) questionnaire.

Results: Twenty-six PA patients and 15 controls were recruited. Biochemical cure of the disease was achieved following surgery in all PA patients; hypertension was cured in 31\% of cases and improved in the remaining 69\% of cases. No morbidity occurred in both groups. There were no significant differences between PA patients and controls concerning demographics, preoperative PCS, MCS and DS values. In patients with PA, MCS values improved at early (42.72 \pm 13.68 vs $51.56 \pm 9.03, p=0.0005)$ and late follow up (42.72 \pm 13.68 vs $51.81 \pm 7.04$, $p<0.0001)$; also DS values improved at early (15.92 \pm 11.98 vs $8.3 \pm 8.8, p=0.0002)$ and late follow up (15.92 \pm 11.98 vs $4.57 \pm 6.11, p<0.0001)$. In PA patients PCS values significantly improved at late follow up (51.02 \pm 8.04 vs $55.85 \pm 5.1$, $p=0.013)$. Also in controls an improvement of MCS and DS scores was found at early and late follow up compared to preoperative values, while no significant differences in PCS were found.
\end{abstract}

Conclusions: Both PA and non-secreting adrenal tumors affect health-related QoL, worsening MCS and DS scores. Adrenalectomy is effective in curing PA, and improving MCS and DS scores at early and late follow-up, in patients with PA and non-secreting adrenal tumors. In PA patient surgery also significantly improves PCS at late follow up.

Keywords: Primary aldosteronism, Quality of life, Depression status, Adrenalectomy

\section{Background}

Primary aldosteronism (PA) due to unilateral or bilateral overproduction of aldosterone, is the most common cause of endocrine hypertension, and it has been reported in more than $11 \%$ of referred hypertensive patients $[1,2]$.

\footnotetext{
* Correspondence: maurizio.iacobone@unipd.it

${ }^{1}$ Endocrine Surgery, Department of Surgery, Oncology and Gastroenterology, University of Padua, Via Giustiniani 2, 35128 Padova, Italy

Full list of author information is available at the end of the article
}

The lateralization of aldosterone hypersecretion is crucial, because only patients with unilateral PA are held to be surgically curable [3]. Unilateral laparoscopic total adrenalectomy is currently the preferred strategy in patients with lateralized excess [4-7].

Besides leading to increased cardiovascular morbidity and mortality [1], PA has been claimed to be associated to higher prevalence of anxiety and depression, with potential impact on health-related quality of life (QoL), through mechanisms and pathways that remain to be clarified $[8,9]$.

(c) The Author(s). 2019 Open Access This article is distributed under the terms of the Creative Commons Attribution 4.0 International License (http://creativecommons.org/licenses/by/4.0/), which permits unrestricted use, distribution, and 
Undoubtedly, both surgical and medical treatment of PA can control hypertension and severe cardiovascular damages in the long term [3]. However, whether these two strategies have the same beneficial effects on QoL and depression remains uncertain. In fact, they show substantial differences, as surgery eliminates the source of aldosterone excess, while mineralocorticoid receptor antagonists simply control it $[10,11]$.

Measurement of QoL investigates the functional status of the individual and the patient's appraisal of health, allowing assessment of the impact of a disease and/or treatment from the patient's perspective.

Therefore, only few studies investigated health-related QoL has been in patients suffering from PA [12, 13], reporting subnormal scores compared to normal population. A recent systematic review, not focusing on this issue, [14] highlighted that, in patients with PA, health-related QoL as well as scores for depression and anxiety [11] ameliorated after surgery with respect to medical treatment.

However, it could not be excluded that non-specific psychological effects secondary to surgery could be at least partly responsible for the improvement in QoL [10].

The aim of the present study was, therefore, to assess the impact of surgery on health related QoL (both in Mental and Physical components) and depression status of patients suffering from PA and to compare them with a control group of patients with non-secreting adrenal tumor who also underwent adrenalectomy.

\section{Methods}

Data were prospectively collected from January 2014 to January 2017 at Endocrine Surgery Unit of Padua University Hospital, Italy.

The present prospective non-randomized study included patients with unilateral PA and a control group of patients with non-secreting adrenal tumor submitted to laparoscopic transperitoneal adrenalectomy by flank approach performed by the same surgeon (M.I.). The institutional ethics committee approved the study and informed consent was obtained from all patients.

PA was diagnosed based on a plasma aldosterone concentration greater than $15 \mathrm{ng} / \mathrm{dL}$ and an aldosterone/ renin ratio greater than $40 \mathrm{ng} / \mathrm{dL}: \mathrm{ng} / \mathrm{mL} / \mathrm{h}$, measured after washout of interfering drugs or after changes of the drug treatment as previously detailed [15]. The diagnosis was confirmed by saline infusion and/or the captopril test [15].

Arterial hypertension was defined by a systolic blood pressure (BP) of $140 \mathrm{mmHg}$ or greater, diastolic BP of $90 \mathrm{mmHg}$ or greater, or both and/or the presence of antihypertensive medical treatment.

Surgery was performed in patients with lateralized PA, according to the results of preoperative lateralizing techniques. Lateralizing techniques included adrenal venous sampling (AVS), CT scan and/or MR as previously described [16].

AVS was performed with bilateral simultaneous catheterization, by using one catheter for each adrenal vein. Successful selective catheterization was usually confirmed when the ratio between cortisol concentration in each adrenal vein and the inferior vena cava was greater than 1.1; unilateral aldosterone hypersecretion was usually confirmed when the ratio of adrenal vein aldosterone concentration to the homolateral cortisol concentration on the side with the higher ratio over the contralateral aldosterone to cortisol ratio (AVS ratio) was greater than 2 .

The control group was composed by patients suffering from non-secreting adrenal tumor, defined as asymptomatic adrenal mass, incidentally detected on imaging not performed for suspected adrenal disease, in patients without glucocorticoid, catecholamine or mineralcorticoid hypersecretion (assessed by plasmatic $\mathrm{ACTH}, 24-\mathrm{h}$ urinary free cortisol levels and $1 \mathrm{mg}$ overnight dexamethasone suppression test, 24-h urinary catecholamine or metanephrine levels and plasma renin and aldosterone levels, respectively). In these patients, surgery was indicated by the presence of adrenal mass with suspicious radiological findings (even without evidence of local invasion or distant metastases), evidence of significant tumor growth during follow-up imaging and/or patient preference. Patients with adrenal or extra-adrenal malignancies or any psychiatric disorders were not included in the study.

The surgical procedure was performed with the patient in lateral decubitus flank position. Pneumoperitoneum (at $12-14 \mathrm{mmHg}$ by $\mathrm{CO}_{2}$ ) was made by Hasson cannula inserted by open technique. A subcostal port was placed for the laparoscope, and two/three other $5 / 10 \mathrm{~mm}$ ports sited. For right adrenalectomy the liver was mobilized and retracted and the right medium adrenal vein was identified by following the lateral edge of the vena cava. The main right adrenal vein was identified and divided early. Then the adrenal branches from the inferior phrenic artery, aorta, and the renal artery were divided. On the left side the colonic flexure was mobilized and the splenorenal ligament dissected, allowing the fall of the spleen medially and the identification of the tail of the pancreas. The avascular plane separating adrenal gland from the tail of the pancreas was opened, allowing the view of the inferior adrenal vein, going into the left renal vein. The inferior adrenal vein was divided and then the gland was dissected and removed. Small arterial vessel from superior, medium and inferior pedicle were coagulated. In all cases, the adrenal gland was removed via a retrieval bag $[7,17]$. 
Health-related QoL and depression status, were assessed preoperatively (at the time of hospital admission) and postoperatively at 1-month outpatient control and at long term (at least 6 months after surgery).

QoL was evaluated using the Italian version of Short Form 36 (SF-36) Health Survey for a Physical (PCS) and a Mental Component (MCS). The SF-36 is a 36 item self-administered questionnaire measuring QoL across eight domains obtaining eight scaled scores, which are the weighted sums of the questions in their section. These domains are physical functioning, social functioning, role limitations due to physical problems, role limitations due to emotional problems, vitality, bodily pain, general health perceptions, and general mental health. PCS and MCS are a summary of physical and emotional QoL respectively. Scores may range from 0 (poorest health status) to 100 (best health status). The depression status was evaluated using a 20-item depression scale (DS) questionnaire; the score may range from 0 (best status) to 60 (poorest status) $[18,19]$. The results were compared with published normative values for the Italian population [20].

Records of the patients were reviewed to gather relevant demographics, body mass index (BMI, defined as body weight $(\mathrm{kg}) /$ height $\left(\mathrm{m}^{2}\right)$, normal values 20 to 24.9), hormonal parameters (including glucocorticoid, mineralcorticoid and catecolamine assays), BP values, number of antihypertensive drugs, side and size of adrenal masses, intra and postoperative morbidity and definitive pathology.

Postoperative follow-up data (including hormonal, BP parameters, number of antihypertensive drugs), were assessed 1 month after surgery and at long-term.

Results were expressed as absolute numbers, ratio, percentage, mean ( \pm standard deviation) or median (range).

Statistical analysis was performed using Fisher's exact test for categorical variables, Student's paired $t$ test, Wilcoxon matched-paired test, Mann-Whitney $U$ test, as appropriate. $p<0.05$ was considered statistically significant.

\section{Results}

Twenty-six PA patients and 15 patients with non-secreting adrenal tumor undergoing laparoscopic transperitoneal adrenalectomy were recruited.

No significant differences were found between PA patients and controls concerning demographics, BMI, side and dimension at preoperative imaging of the mass (Table 1). The size of the adrenal mass at preoperative imaging was significantly higher in controls than in PA patients $(p<0.0001)$ (Table 1$)$

Hypertension was present in all patients with PA and in five patients with non-secreting adrenal tumor $(p<0.0001)$; hence, the mean systolic and diastolic BP were significantly higher in PA patients than in controls (154 \pm 19 vs $125 \pm 9 \mathrm{mmHg}, p<0.0001$ and $91 \pm 12$ vs $75 \pm 8 \mathrm{mmHg}, \quad p=0.0002$, respectively); likewise, the number of antihypertensive drugs was significantly higher in PA patients than in controls $(3.42 \pm 1.47$ vs $0.60 \pm 0.99, p<0.0001)$.

Preoperative MCS and DS scores were impaired in PA patients compared to normal Italian reference population; similar findings were found also in the control patients.

No significant differences were found between PA patients and controls concerning preoperative PCS $(51.02 \pm 8.04$ vs $51.16 \pm 9.63, p=0.75), \operatorname{MCS}(42.72 \pm$ 13.68 vs $39.39 \pm 12.81, p=0.39)$, and DS values $(15.92 \pm$ 11.98 vs $16.26 \pm 12.56, p=0.91)$.

All patients underwent uneventful laparoscopic surgery; no conversion to open approach was performed, no blood transfusion was required and no intra- or post-operative morbidity occurred in both groups.

Pathological specimens revealed benign adrenal tumors in all cases in both groups.

\section{Early follow-up}

At one month postoperative follow up, PA was biochemically cured in all patients, according to the normalization of the aldosterone/renin ratio and serum potassium levels; hypertension was cured in 10 cases (38\%), and improved in the remaining 16 cases $(62 \%)$. The systolic and diastolic BP were significantly reduced (from $154 \pm 19$ to $130 \pm 15 \mathrm{mmHg}, p<0.0001$ and from $91 \pm 12$ to $78 \pm 9 \mathrm{mmHg}, p<0.0001$ ); also the mean number of antihypertensive drugs was significantly reduced (from $3.42 \pm 1.47$ to $1.15 \pm 1.1, p<0.0001$ ).

In patients with PA, MCS values significantly improved (42.72 \pm 13.68 vs $51.56 \pm 9.03, p=0.0005$ ) (Fig. 1 ), mainly due to an amelioration in the "mental health" $(42.7 \pm 15.7$ vs $53.17 \pm 7.33, p=0.001)$ and "emotional role" $(45.5 \pm 11.83$ vs $51.23 \pm 9.84, \mathrm{p}=0.001)$ scores. Also DS values significantly improved $(15.92 \pm 11.98$ vs $8.3 \pm$ $8.8, p=0.0002)$. Conversely, no quite significant differences were found regarding PCS scores (51.02 \pm 8.04 vs $48.01 \pm 6.85, p=0.07$ ) (Fig. 1).

In controls, no significant changes in BP levels and number of antihypertensive drugs was found; also in the five hypertensive patients no changes in BP values and number of antihypertensive drugs were detected after adrenalectomy.

Also in controls MCS $(39.39 \pm 12.81$ vs $50.62 \pm 8.68$, $p=0.0005)$ and DS $(16.26 \pm 12.56$ vs $7.86 \pm 7.19, p=0.001)$ values improved after surgery, mainly due to a significant amelioration in the "mental health" $(46.69 \pm 12.01$ vs $53.79 \pm 6.36, p=0.006)$ and "emotional role" (33.19 \pm 
Table 1 Demographics, and general features in (PA patients) patients with Primary Aldosteronism and controls undergoing laparoscopic adrenalectomy

\begin{tabular}{llll}
\hline & PA Patients $(n=26)$ & Controls $(n=15)$ & $P$ value \\
\hline Sex (female/male) & $10 / 16$ & $6 / 9$ & 0.92 \\
Age (years) & $54 \pm 11$ & $56 \pm 9$ & 0.54 \\
Body Mass Index $\left(\mathrm{kg} / \mathrm{m}^{2}\right)$ & $26.6 \pm 4$ & $27.4 \pm 6$ & 0.95 \\
Side of the mass (left/right) & $12 / 14$ & $9 / 6$ & 0.59 \\
Size of the mass (mm) median (range) & $15(6-30)$ & $44(25-60)$ & $<0.0001$ \\
\hline
\end{tabular}

PA Primary aldosteronism

13.69 vs $46.93 \pm 9.26, p=0.001$ ) scores (Fig. 1). No significant differences were found regarding PCS values $(51.16 \pm 9.63$ vs $48.60 \pm 6.99 p=0.26)$.

No significant differences were found between PA and control patients concerning postoperative MCS and PCS and DS $(p=0.69, p=0.81$ and $p=0.93$, respectively).

\section{Long term follow up}

At long term follow up (median 8 months, range 6-13), all patients that underwent surgery for PA were still biochemically cured, but two patients that at one month had achieved the cure of hypertension, restarted antihypertensive therapy; thus, the hypertension cure was achieved in 8 patients (31\%).

\section{PA PATIENTS}
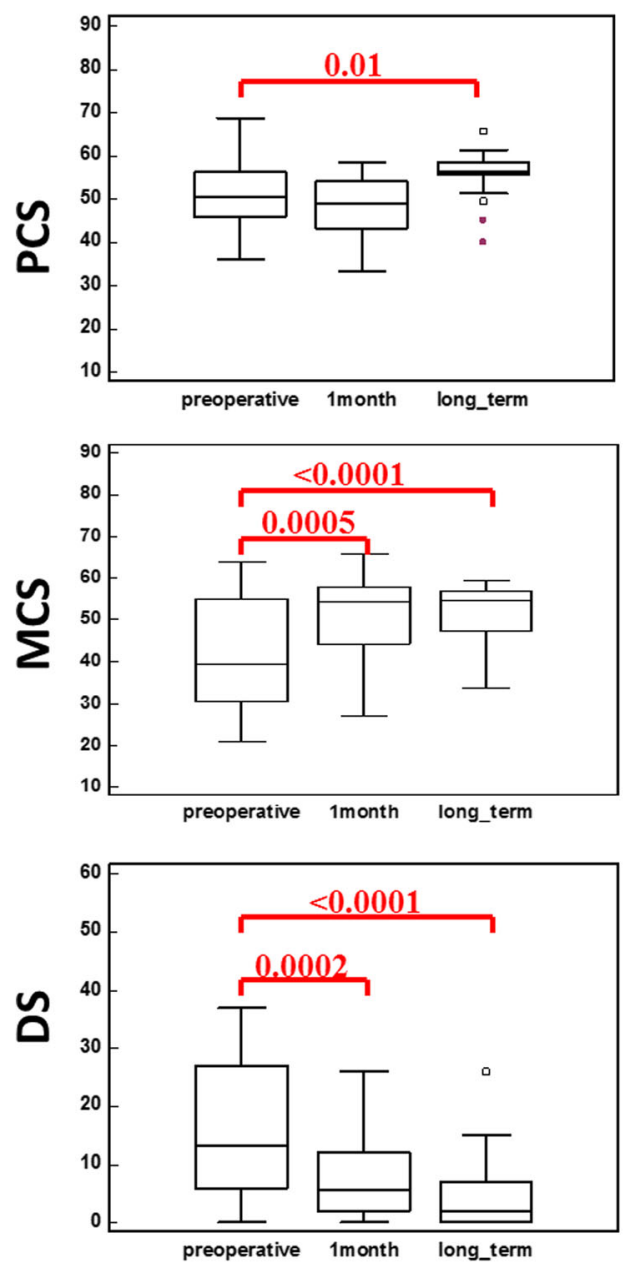

\section{CONTROLS}
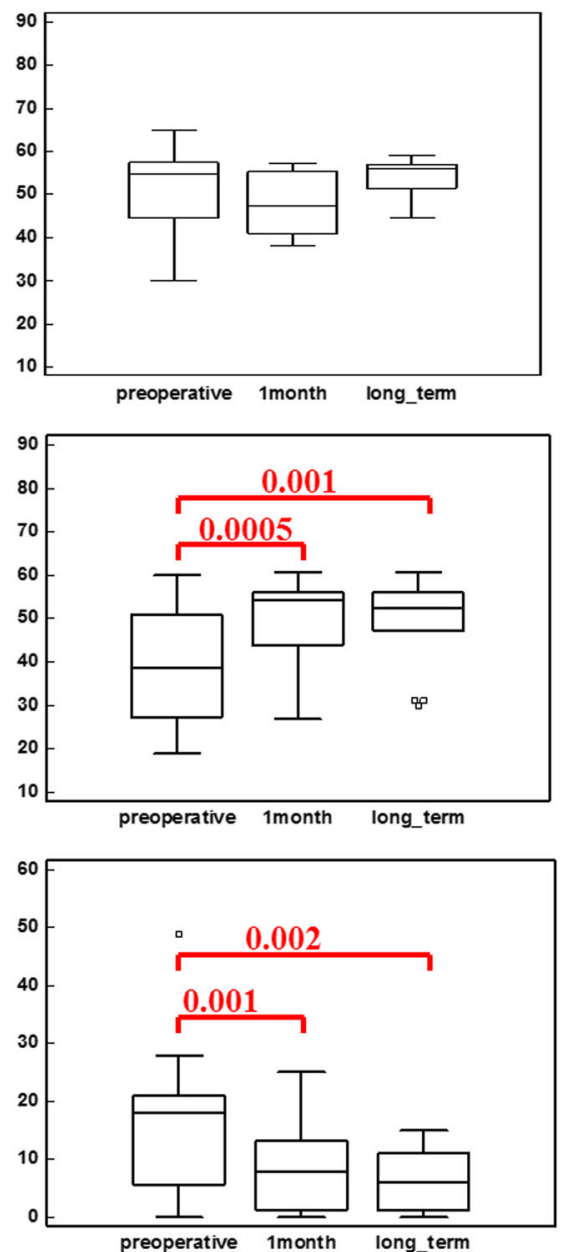

Fig. 1 PCS, MCS and DS values in PA patients and controls, preoperatively, 1 month after surgery and at long term. PA: primary aldosteronism; PCS: Physical Component Score; MCS: Mental Component Score; DS: depression scale 
PA patients had systolic and diastolic BP values significantly reduced (from $154 \pm 19$ to $129 \pm 13 \mathrm{mmHg}$, $p<0.0001$ and from $91 \pm 12$ to $79 \pm 8 \mathrm{mmHg}, p<0.0001$ ), compared with preoperative values; also the mean number of antihypertensive drugs was significantly reduced (from $3.42 \pm 1.47$ to $1.28 \pm 1.2, p<0.0001)$.

These patients had no significant differences in BP values and number of antihypertensive drugs one month after surgery and at long term follow up.

In patients with PA, a significant improvement in PCS $(51.02 \pm 8.04$ vs $55.85 \pm 5.1, p=0.013), \operatorname{MCS}(42.72 \pm$ 13.68 vs $51.81 \pm 7.04, p<0.0001)$ and DS $(15.92 \pm 11.98$ vs $4.57 \pm 6.11, p<0.0001)$ values was described, compared with preoperative period; PCS values improved significantly, compared with values recorded one month after surgery ( $p=0.0002)$ (Fig. 1$)$.

At late follow up, also in controls MCS (39.39 \pm 12.81 vs $49.30 \pm 10.46, p=0.001)$ and DS values $(16.26 \pm 12.56$ vs $6.80 \pm 5.64, p=0.002$ ) improved after surgery, mainly due to a significant amelioration in the "mental health" $(46.69 \pm 12.01$ vs $54.64 \pm 7.87, p=0.007)$ and "emotional role" $(33.19 \pm 13.69$ vs $51.62 \pm 9.87, p<0.0001)$ scores (Fig. 1). No significant differences were found regarding PCS values $(51.16 \pm 9.63$ vs $53.91 \pm 4.30 p=0.25)$.

No significant differences were found between PA and control patients concerning MCS and PCS and DS $(p=0.58, p=0.16$ and $p=0.18$, respectively).

\section{Discussion}

PA is a common, albeit often overlooked, cause of hypertension which is often severe and/or drug resistant and, therefore, associated with cardiovascular damage and a worse prognosis [21, 22]. Moreover, it implies clear cut alterations of the renin-angiotensin-aldosterone system, which suggests that it entails multiple reasons to imply a worsened QoL, given that the derangements of this important system can affect QoL $[8,9]$.

Hypertension is an important factor for reduced QoL: an impairment of QoL has been reported in patients with essential hypertension compared to normal controls in the somatization and psychological distress [23].

Along with this hypothesis, at the best of our knowledge, Health-related QoL in patients suffering from PA has been previously investigated only by 3 studies [12, 13, 24].

In 2010, Sukor et al. [24] examined health-related QoL in 22 patients with unilateral PA before and after unilateral adrenalectomy at 3 and 6 months, using SF-36 questionnaire. They found a significant improvement in the QoL of these patients both in physical and mental condition. However, they did not examine depression and anxiety.

In 2011, the same authors [12] compared the results of the previous study with those from 21 patients with bilateral PA, before or after commencing medical treatment, and with those of the normal Australian population. They confirmed that PA patients had subnormal QoL scores compared to normal population. Moreover, they described that QoL improved in all patients with bilateral PA undergoing medical treatment, but more slowly and to a lesser degree than in patients undergoing surgery for unilateral PA.

In 2012, Kunzel et al. [13] published the results of a cross sectional study on the data from German Conn Registry examining health-related QoL using SF12 questionnaire, in which they investigated acute impairment of QoL and long-term treatment effects in patients with PA. The study included 132 patients with PA, stratified according to the treatment status: 27 newly diagnosed, untreated; 52 in chronic medical treatment, 49 patients treated with adrenalectomy. The study confirmed that PA patients had a worse physical and mental condition than the normal German reference population; untreated and medically treated patients reported the lowest scores.

Our study differed substantially from these previous studies, since we enrolled as controls patients undergoing the same surgical procedure for non-functioning adrenal mass.

This allowed adjustment for the potentially confounding effect of being harboring an adrenal tumor and of being submitted to adrenalectomy. Moreover, our study was aimed to clarify the impact of surgery on health-related QoL (both in Mental and Physical components) and for the first time on depression status, in patients suffering from PA.

In agreement with previous studies, we confirmed that patients with PA have an impaired QoL and depression status compared with normal population, as assessed by worse MCS and DS scores.

In PA patients, MCS (especially in the mental health and emotional role dimensions) and DS values significantly improved 1 month after surgery and at long term follow-up, confirming the beneficial effect of adrenalectomy previously reported [12]. However, we failed to find significant differences with the controls, since also these patients (without aldosterone excess) showed an impaired preoperative MCS and DS scores, and a significant amelioration one month and at long term after surgery. Interestingly, also in controls MCS improvement was mainly due to mental health and emotional role amelioration. However, the amelioration was more evident in PA patients.

Even if controls and PA patients were similar according to demographics and type of surgical procedure, the former had lower BP levels, larger adrenal masses and underwent surgery mainly because of a suspicion of malignancy, while there was not suspicion for the latter. 
Thus, it remains unclear if it may be related to the reduction of BP levels or antihypertensive drug treatment (with a possible reduction of drug-related size effects), to the aldosterone/renin system normalization or a non-specific psychological effect of surgery.

We may argue that in control population the thought of impending surgery and the uncertain nature of the non-secreting adrenal mass might have affected the mental component and increased the depression status before surgery. Obviously, both factors might have been solved after surgery, since in all cases definitive pathology described a benign adrenal tumor; however, other psychologic effects of adrenalectomy may not be excluded, as previously reported [10].

In the present study, no significant amelioration of PCS scores was detected in PA patients one month after surgery; this finding might be related to the sequelae of recent surgery. In fact, in PA patients the improvement in PCS values become evident at long term follow-up. This is in agreement with previous studies that demonstrated at 3 months a significant increase of physical condition, after disease cure and BP normalization or amelioration [24].

In the control group, no significant variations were detected in PCS values at one month and at long term, compared with preoperative values.

However, some limitations to the present pilot study that might have biased the results should be underlined, including the limited number of cases and length of follow up. Moreover, the mental component of healthrelated QoL is difficult to explore; the SF-36 and DS questionnaires are not disease specific. Furthermore, the administration of the baseline questionnaire during hospitalization for surgery, when factors such as optimism or anxiety and fear of surgery could have some effects, might have affected the results in terms of worsening QoL and depression as compared to the normal population. However, if any, the effect was likely similar in both PA and controls.

\section{Conclusions}

PA affects the health-related QoL, worsening the mental component and the depression status. Adrenalectomy is effective in curing PA, and improves the mental component of health-related QoL and depression status at 1 month and at long term. At long term, surgery determines an improvement also in the physical component of health-related QoL of PA patients.

The role of hormonal cure of PA and the possible weight of the psychological effects of surgery itself in affecting QoL need to be further explored, since some relevant results may be observed also in patients undergoing surgery for non-secreting adrenal masses. Further studies are needed to confirm these results at a longer follow up and with a larger population.

\section{Abbreviations}

ACTH: Adrenocorticotropic hormone; AVS: Adrenal vein sampling; BMl: Body mass index; BP: Blood pressure; CT scan: Computed tomography; DS: Depression scale questionnaire; MCS: Health Survey for Mental Component; MR: Magnetic resonance; PA: Primary aldosteronism; PCS: Health Survey for Physical Component; QoL: Quality of life; SF-36: Short Form 36

\section{Acknowledgements \\ The authors wish to thank Senthilkumar Rajendran for helping in English revision.}

\section{Funding}

The study was supported by a grant to Maurizio lacobone from University of Padua, Italy (DOR 2016-1638917), that had no role in the study design, collection, analysis and interpretation of data nor in the writing of the manuscript and in the decision to submit the manuscript for publication.

\section{About this supplement}

This article has been published as part of BMC Surgery Volume 18 Supplement 1 , 2018: Updates and New Technology in Endocrine Surgery. The full contents of the supplement are available online at https://bmcsurg.biomedcentral.com/articles/ supplements/volume-18-supplement-1.

Availability of data and materials

The datasets used and/or analysed during the current study are available from the corresponding author on reasonable request.

\section{Authors' contributions}

MC: Study conception and design, Acquisition of data, Analysis and interpretation of data, Drafting of manuscript, Critical revision of manuscript. GV: Acquisition of data, Critical revision of manuscript. FT: Acquisition of data, Critical revision of manuscript. GPR: Study conception and design, Analysis and interpretation of data, Drafting of manuscript, Critical revision of manuscript. MI: Study conception and design, Analysis and interpretation of data, Drafting of manuscript, Critical revision of manuscript. All of the authors have read and approved the final manuscript.

Ethics approval and consent to participate

The study was approved by the Padua University Hospital Ethic Committee (Italy). All procedures performed in studies involving human participants were in accordance with the ethical standards of the institutional and/or national research committee and with the 1964 Helsinki declaration and its additional amendments or comparable ethical standards.

\section{Consent for publication}

Written informed consent was obtained from all patients prior to their inclusion in the study.

\section{Competing interests}

The authors declare that they have no competing interests.

\section{Publisher's Note}

Springer Nature remains neutral with regard to jurisdictional claims in published maps and institutional affiliations.

\section{Author details}

${ }^{1}$ Endocrine Surgery, Department of Surgery, Oncology and Gastroenterology, University of Padua, Via Giustiniani 2, 35128 Padova, Italy. ${ }^{2}$ Hypertension Clinic, Department of Medicine, University of Padua, Via Giustiniani 2, 35128 Padova, Italy.

Received: 17 September 2018 Accepted: 29 October 2018 Published: 24 April 2019

\section{References}

1. Rossi GP, Bernini G, Desideri G, Fabris B, Ferri C, Giacchetti G, Letizia C, Maccario M, Mannelli M, Matterello MJ, Montemurro D, Palumbo G, Rizzoni $D$, Rossi E, Pessina AC, Mantero F. Renal damage in primary aldosteronism: results of the PAPY study. Hypertension. 2006;48:232-8. https://doi.org/10. 1161/01.HYP.0000230444.01215.6a. 
2. Funder JW, Carey RM, Fardella C, Gomez-Sanchez CE, Mantero F, Stowasser M, Young WF Jr, Montori VM, Endocrine Society. Case detection, diagnosis, and treatment of patients with primary aldosteronism: an endocrine society clinical practice guideline. J Clin Endocrinol Metab. 2008;93:3266-81. https://doi.org/10.1210/jc.2008-0104.

3. Rossi GP, Cesari M, Cuspidi C, Maiolino G, Cicala MV, Bisogni V, Mantero F, Pessina AC. Long-term control of arterial hypertension and regression of left ventricular hypertrophy with treatment of primary aldosteronism. Hypertension. 2013;62:62-9. https://doi.org/10.1161/HYPERTENSIONAHA.113. 01316.

4. lacobone M, Citton M, Viel G, Rossi GP, Nitti D. Approach to the surgical management of primary aldosteronism. Gland Surg. 2015;4:69-81. https://doi.org/10.3978/j.issn.2227-684X.2015.01.05.

5. Henry JF, Sebag F, lacobone M, Hubbard J, Maweja S. Lessons learned from 274 laparoscopic adrenalectomies. Ann Chir. 2002;127:512-9 PubMed PMID: 12404845

6. Lumachi F, Ermani M, Basso SM, Armanini D, lacobone M, Favia G. Longterm results of adrenalectomy in patients with aldosterone-producing adenomas: multivariate analysis of factors affecting unresolved hypertension and review of the literature. Am Surg. 2005;71:864-9 PubMed PMID: 16468537.

7. Henry JF, Sebag F, lacobone M, Mirallie E. Results of laparoscopic adrenalectomy for large and potentially malignant tumors. World J Surg. 2002;26:1043-7 PubMed PMID: 12045859

8. Emanuele E, Geroldi D, Minoretti P, Coen E, Politi P. Increased plasma aldosterone in patients with clinical depression. Arch Med Res. 2005:36:544-8 PubMed PMID: 16099336

9. Jezova D, Hlavacova N. Endocrine factors in stress and psychiatric disorders: focus on anxiety and salivary steroids. Ann N Y Acad Sci. 2008;1 148:495-503. https://doi.org/10.1196/annals.1410.050.

10. Sonino N, Tomba E, Genesia ML, Bertello C, Mulatero P, Veglio F, Fava GA, Fallo F. Psychological assessment of primary aldosteronism: a controlled study. J Clin Endocrinol Metab. 2011;96:E878-83. https://doi.org/10.1210/jc 2010-2723.

11. Apostolopoulou K(1), Künzel HE, Gerum S, Merkle K, Schulz S, Fischer E, Pallauf $A$, Brand V, Bidlingmaier M, Endres S, Beuschlein F, Reincke M. Gender differences in anxiety and depressive symptoms in patients with primary hyperaldosteronism: a cross-sectional study. World J Biol Psychiatry 2014;15:26-35. doi: https://doi.org/10.3109/15622975.2012.665480.

12. Ahmed AH, Gordon RD, Sukor N, Pimenta E, Stowasser M. Quality of life in patients with bilateral primary aldosteronism before and during treatment with spironolactone and/or amiloride, including a comparison with our previously published results in those with unilateral disease treated surgically. J Clin Endocrinol Metab. 2011;96:2904-11. https://doi.org/10.1210/ jc.2011-0138.

13. Künzel HE, Apostolopoulou K, Pallauf A, Gerum S, Merkle K, Schulz S, Fischer E, Brand V, Bidlingmaier M, Endres S, Beuschlein F, Reincke M. Quality of life in patients with primary aldosteronism: gender differences in untreated and long-term treated patients and associations with treatment and aldosterone. J Psychiatr Res. 2012;46:1650-4. https://doi.org/10.1016/j. jpsychires.2012.08.025.

14. Muth A, Ragnarsson O, Johannsson G, Wängberg B. Systematic review of surgery and outcomes in patients with primary aldosteronism. Br J Surg. 2015;102:307-17. https://doi.org/10.1002/bjs.9744.

15. Rossi GP, Seccia TM, Pessina AC. A diagnostic algorithm—the holy grail of primary aldosteronism. Nat Rev Endocrinol. 2011;7:697-9. https://doi.org/10. 1038/nrendo.2011.180

16. Citton M, Viel G, Rossi GP, Mantero F, Nitti D, lacobone M. Outcome of surgical treatment of primary aldosteronism. Langenbeck's Arch Surg. 2015:400:325-31. https://doi.org/10.1007/s00423-014-1269-4.

17. Conzo G, Gambardella C, Candela G, Sanguinetti A, Polistena A, Clarizia G, Patrone R, Di Capua F, Offi C, Musella M, lorio S, Bellastella G, Pasquali D, De Bellis A, Sinisi A, Avenia N. Single center experience with laparoscopic adrenalectomy on a large clinical series. BMC Surg. 2018;18:2. https://doi.org/10.1186/s12893-017-0333-8.

18. Rossi GP, Seccia TM, Gallina V, Muiesan ML, Leoni L, Pengo M, Ragazzo F, Caielli P, Belfiore A, Bernini G, Cipollone F, Cottone S, Ferri C, Giacchetti G, Grassi G, Letizia C, Maccario M, Olivieri O, Palumbo G, Rizzoni D, Rossi E, Sechi L, Volpe M, Mantero F, Morganti A, Pessina AC. Prospective appraisal of the prevalence of primary aldosteronism in hypertensive patients presenting with atrial flutter or fibrillation (PAPPHY study): rationale and study design. J Hum Hypertens. 2013;27:158-63. https://doi.org/10.1038/jhh.2012.21.

19. Van Dam NT, Earleywine M. Validation of the Center for Epidemiologic Studies Depression Scale-Revised (CESD-R): pragmatic depression assessment in the general population. Psychiatry Res. 2011;30(186):128-32. https://doi.org/10.1016/j.psychres.2010.08.018.

20. Apolone G, Mosconi P. The Italian SF-36 health survey: translation, validation and norming. J Clin Epidemiol. 1998;51:1025-36 PubMed PMID: 9817120.

21. Douma S, Petidis K, Doumas M, Papaefthimiou P, Triantafyllou A, Kartali N, Papadopoulos N, Vogiatzis K, Zamboulis C. Prevalence of primary hyperaldosteronism in resistant hypertension: a retrospective observational study. Lancet. 2008;371:1921-6. https://doi.org/10.1016/S01406736(08)60834-X.

22. Milliez P, Girerd X, Plouin PF, Blacher J, Safar ME, Mourad JJ. Evidence for an increased rate of cardiovascular events in patients with primary aldosteronism. J Am Coll Cardiol. 2005;45:1243-8. https://doi.org/10.1016/j. jacc.2005.01.015.

23. Coelho AM, Coelho R, Barros H, Rocha-Gonçalves F, Reis-Lima MA. Essential arterial hypertension: psychopathology, compliance, and quality of life. Rev Port Cardiol. 1997;16:873-83 PubMed PMID: 9477720.

24. Sukor N, Kogovsek C, Gordon RD, Robson D, Stowasser M. Improved quality of life, blood pressure, and biochemical status following laparoscopic adrenalectomy for unilateral primary aldosteronism. J Clin Endocrinol Metab. 2010:95:1360-4. https://doi.org/10.1210/jc.2009-1763.
Ready to submit your research? Choose BMC and benefit from:

- fast, convenient online submission

- thorough peer review by experienced researchers in your field

- rapid publication on acceptance

- support for research data, including large and complex data types

- gold Open Access which fosters wider collaboration and increased citations

- maximum visibility for your research: over $100 \mathrm{M}$ website views per year

At BMC, research is always in progress.

Learn more biomedcentral.com/submissions 